\title{
UPDATE ON WORK-EXACERBATED ASTHMA
}

\author{
SUSAN M. TARLO \\ University of Toronto, Toronto, Ontario, Canada \\ Toronto Western Hospital
}

\begin{abstract}
Work-exacerbated asthma (WEA) is the term used to describe the worsening of asthma related to work but not the causation of asthma by work. It is common and has been reported to occur for $21.5 \%$ of working asthmatics on average. The frequency and severity may range from a single mild exacerbation that may lead to no time lost at work up to daily or severe exacerbations that may require a permanent change in work. Reports from general population surveys and primary care settings include more patients with short-term or mild exacerbations while those from tertiary care settings reflect the more severe end of the spectrum of severity or frequency, with socioeconomic outcomes that are similar to those of occupational asthma. In the minority of patients with the WEA, whose asthma starts while working, the differential diagnosis includes sensitizer-induced or possible irritant-induced occupational asthma. Optimizing work exposures and asthma management may improve outcome and prevent exacerbations. Worker education and screening of working asthmatics by primary health care workers may also prevent morbidity.
\end{abstract}

Key words:

Asthma, Work-related asthma, Work-exacerbated asthma, Work-aggravated asthma, Work, Occupation

\section{INTRODUCTION}

Work-exacerbated asthma (WEA), also termed workaggravated asthma, describes a sub-set of work-related asthma that is worsened but not caused by work (unlike occupational asthma that is caused by work). Work-exacerbated asthma is common, and in studies of adult working asthmatics it has been reported to occur for $21 \%$ of patients or more [1]. Older literature on work-related asthma had focused mainly on occupational asthma but especially in the past 5-10 years there has been increasing interest in WEA.

An American Thoracic Society (ATS) Statement in 2011 [1] reviewed papers from a literature search combining the terms asthma, occupation, and exacerbation from 1980 to 2009 and identified 140 relevant articles. The panel developed a case definition that there was preexisting or concurrent onset of asthma (i.e., asthma was not caused by work), a temporal relationship of asthma to work (from history \pm peak flow recordings), conditions at work that could exacerbate asthma (i.e., respiratory irritants or other asthma triggers), and a finding that occupational asthma was unlikely to explain findings. However, they acknowledged that those with occupational asthma could subsequently develop WEA or vice versa, as previously suggested in an American College of Chest Physicians Consensus Statement on work-related asthma [2].

\section{PREVALENCE AND FEATURES OF WEA}

The ATS Statement identified 12 general population or primary health care studies up to 2009 with the WEA prevalence of $13-58 \%$ of working asthmatics, that is $21.5 \%$ on average [1]. The wide range in prevalence was thought likely to reflect differences used in definition with lower rates when criteria were more stringent. Many 
of the surveillance studies were based on the questionnaire only and only $5 \%$ of cases from studies conducted in the United States and Canada had pulmonary function to support the work association. Additionally many of these episodes were transient and infrequent, and would have been difficult to document objectively without routine peak flow or spirometry monitoring of patients.

Since the ATS Statement, a similar prevalence of WEA among asthmatics has been reported. A recent review by Fishwick et al. [3] has also found a median prevalence of WEA at $21.5 \%$ among workers with asthma, and a prevalence of $22 \%$ of work-related asthma has been reported by history among Iranian adult asthma patients. Additionally, a report of severe exacerbations leading to a hospital admission or corticosteroid burst among working asthmatics in a US primary care health maintenance organization (HMO) setting has found that $29 \%$ of the asthmatics had had a severe exacerbation in the previous year and overall $41 \%$ of all asthmatics had had an exposure to a potential work trigger (an irritant or sensitizer) as estimated by a job-exposure matrix [4].

Detailed investigations have not been reported so it is uncertain how many of those patients may have had occupational asthma rather than WEA. A recent report from a population telephone survey among adults in 22 states in the US has identified $9 \%$ with reported current asthma and $15.7 \%$ of these reported that they had ever been told by a doctor or other health professional that their asthma had been caused by, or symptoms made worse by, any job they ever had [5] again, emphasizing the common occurrence of work-related asthma. Although WEA could also not be differentiated in this report from the occupational asthma (OA), it may be suspected that most reports were from WEA. Among adults with asthma, from a US national health interview survey, $28.1 \%$ reported that they were frequently exposed to workplace vapors, gas, dust or fumes [6], exposures that could be expected to exacerbate asthma.
In contrast to studies of general population or primary care populations, others have addressed features of WEA among those referred to specialist tertiary care centers for assessment of work-related asthma. Within such centers patients are most likely to be referred for assessment if they have frequent exacerbations associated with work, and/or have the suspicion of possible occupational asthma due to the new-onset of asthma while working, or an exposure to a known sensitizing agent at work. Likely due to this referral bias, in many reported series from such centers the diagnosis of WEA has been made by exclusion of occupational asthma (often based on a negative specific inhalation challenge test to workplace agents). Therefore it may be expected that these patients with WEA would have different features from those identified in more general asthma populations. This has been addressed in a study that has retrospectively compared patients with WEA from an American HMO (primary care setting), and 2 specialist work-related asthma clinics in Canada where detailed investigations were performed including specific inhalation challenge tests [7].

As might be expected, the asthmatics with WEA in the tertiary clinics have had more severe asthma than those in primary care: $75 \%$ among the tertiary clinic patients versus $11 \%$ in primary care had at least 3 physician visits for their asthma in the preceding year. Also as may be expected, those with WEA in primary care versus tertiary clinics have had a longer mean duration of asthma and were more likely to have had the onset of asthma in childhood. Additionally, those with WEA in the tertiary clinic have been more likely to work in manufacturing versus those with WEA in primary care where the 3 most common occupations have been in office and administrative support, health care and sales and related work: settings, commonly thought to be less likely to have persistent daily triggers to asthma.

Among those with work-related asthma from tertiary clinics, WEA has generally been similar in frequency or 
slightly less common compared with occupational asthma, when the diagnosis is reached on the basis of a negative specific inhalation challenge test and/or other detailed investigations for occupational asthma [8-13]. However, in this group with WEA, health utilization [12] and the socio-economic outcomes [14] have been similar to those reported with occupational asthma.

Therefore there is a wide range of frequency and severity of WEA, ranging from a single mild exacerbation at work that may be treated by the worker with a short term increase in asthma medication and no lost time from work, to more severe exacerbation(s) leading to emergency visits and lost time from work, up to frequent or daily symptoms worse at work that may mimic occupational asthma and require full investigations for diagnosis, subsequently often leading to a need for changes in work exposure in addition to adjustment of pharmacologic management of asthma.

Patients with WEA are not supported by workers' compensation systems in all jurisdictions but in Canada, the workers' compensation system in the province of Ontario does accept claims for WEA. Review of accepted Ontario claims has shown that in recent years the numbers compensated for occupational asthma have fallen while those compensated for WEA, have steadily risen both as a proportion of all accepted asthma claims and in absolute numbers. The number accepted as due to WEA has been similar to the number accepted as occupational asthma in the early 1990s [15] but by 1998-2002 73\% of all accepted asthma claims were WEA [16]. The accepted WEA claims have been more similar to those previously described from primary care studies: $68 \%$ have not had a specialist assessment but have seen for their exacerbation by a primary care physician or emergency physician, and $40 \%$ have missed less than a day of work due to their exacerbation while 17\% missed 6-19 days of work and $10 \%$ missed $>19$ days. Only $15 \%$ have been assessed by a respiratory physician and the majority has had management by primary care physicians without specialist assessment. Similar to the WEA studies reported from primary care, the most common occupations have been in service, education, and health care $[15,16]$.

As noted above, and as expected, most cases have had transient symptoms and little if any time missed from work, and these claims have been allowed mainly on the basis of the history of exposure and worsened symptoms without detailed objective tests. Some differences have been identified between the 3 main work sectors for implicated exposures and time lost from work [16], the WEA cases in the education sector have been more likely to take a longer time off work and those in the health care sector least likely. Dusts have been the most common implicated agents in healthcare and education, while smoke has been more common in service jobs [16]. Education workers (teachers and other staff) have been more likely to have claims during the period of a strike of school cleaners [17].

\section{DIAGNOSIS OF WEA}

For short single exacerbations, the diagnosis of WEA is often made on the basis of a known diagnosis of asthma and a history of exposure at work to an expected asthma trigger, with associated reported worsening asthma symptoms. For more frequent exacerbations, objective investigations may be performed. The tests performed are the same as used to investigate occupational asthma $[2,18,19]$. In the common context of preceding asthma, prior to the work exposures, and/or an absence of a specific sensitizer at work, the findings of work-related worsening of asthma documented by serial peak expiratory flow recordings, symptoms and medications are supportive of WEA.

However, it may be difficult to distinguish WEA from occupational asthma in those patients who have the concurrent onset of asthma while working and/or have exposure to a known respiratory sensitizer at work. The results of peak expiratory flow monitoring, and even shifts in paired 
methacholine tests and induced sputum eosinophil offwork versus at-work may show similar changes in those with the WEA and those with OA [9].

Positive immunologic tests to a work sensitizer (skin tests or in vitro specific immunoglobulin $\mathrm{E}(\mathrm{IgE}))$ may be helpful, but may be positive in a proportion of workers who do not have asthma. Wiszniewska et al. [20] have reported that specific $\operatorname{IgE}$ antibodies to flour were found in $61.7 \%$ of bakery workers with OA and $28.6 \%$ of those with WEA (using specific inhalation challenges with the flour from the workplace to distinguish WEA from occupational asthma: with WEA based on a negative specific challenge). Even specific challenge tests may not always provide an accurate distinction between OA and WEA since there may be false negative challenge results, e.g., if tests do not include the relevant sensitizer [21].

\section{Differential diagnosis of WEA}

\section{from irritant-induced asthma}

Although most investigations have aimed to distinguish WEA and OA using the methods described above, recent attention has been raised to the possibility that some cases among the minority of apparent WEA with the new-onset of asthma while working may truly be caused by prolonged moderate-level irritant exposures at work that do not fit the criteria usually used for the diagnosis of irritant-induced asthma [22].

Epidemiological studies have suggested increased frequency of new-onset asthma among workers exposed to agents that may be expected to be irritants but have not often been clearly shown to be respiratory sensitizers. These include sprayed cleaning products, wood dusts, dusts in swine and dairy production, and welding fumes [22]. The European Academy of Allergy, Asthma, Clinical Immunology Task Force Statement has classified this as "possible irritant-induced occupational asthma" [22]. This diagnosis is circumstantial and the degree of probability for this can only be based at present on the odds ratio for new asthma among epidemiological studies with the same exposures.

\section{MANAGEMENT AND OUTCOME}

The patient with an exacerbation of asthma from work requires management as for any asthmatic with an exacerbation. General advice when an exacerbation occurs at work is to leave the area of exposure and use appropriate asthma medication. If severe an emergency visit or assessment with a physician may be needed and time off work may be needed to recover. Identification of the triggering factor(s) is important. Potentially the worker may have symptoms triggered even with usual work exposures that generally do not affect them, if they have an upper respiratory infection or at a time when usual maintenance medications have been missed. In that event the worker may be able to return to their usual work environment after recovery from the exacerbation. Alternatively, there may have been an unusual exposure at work that triggered the exacerbation that will not be present after the worker returns to work.

If the work trigger is still present after the exacerbation, then approaches to management include optimizing asthma medications, reducing exposures to asthma triggers where possible (e.g., a change in process or better ventilation), or potentially short-term use of respiratory protective devices when appropriate. If these are not sufficient then a move to a cleaner work area may be necessary [2]

\section{Prevention of WEA}

Primary preventive measures include appropriate exposure controls in the workplace and optimum general management of asthma. Even with these measures, the patient who has severe asthma or who has a worsening of asthma, e.g., with a respiratory viral infection, may have an exacerbation at work with exposures that are within allowable standards, or at levels that the patient may usually tolerate without difficulty. For transient worsening of asthma severity there may be a need for a move to a cleaner environment 
or time off work, at least on a temporary basis. For patients with ongoing more severe asthma relocation to a cleaner job may be needed to prevent exacerbations.

Patient education may also contribute to the primary preventive WEA measures. Potentially this may be delivered by asthma educators or by written materials or web-based educational tools, such as a tool available through the $\mathrm{Ca}$ nadian Lung Association [23].

Secondary prevention includes early identification of patients with WEA and appropriate management. It has been found that social factors and workplace factors may delay the time to diagnosis of WEA as well as OA [13]. There is a need for primary health care workers to ask their asthmatic patients as to possible work-related asthma, and this may be assisted by primary care asthma screening programs $[24,25]$.

\section{CONCLUSIONS}

Work-exacerbated asthma is common and likely underrecognized. When severe and when asthma has started while working, WEA may mimic OA and may have a similar socio-economic impact. Early recognition and intervention may reduce the morbidity associated with this.

\section{REFERENCES}

1. Henneberger PK, Redlich CA, Callahan DB, Harber P, Lemière $\mathrm{C}$, Martin J, et al. An official American Thoracic Society Statement: Work-exacerbated asthma. Am J Respir Crit Care Med. 2011;184(3):368-78, http://dx.doi.org/10.1164/ rccm.812011ST.

2. Tarlo SM, Balmes J, Balkissoon R, Beach J, Beckett W, Bernstein D, et al. Diagnosis and management of work-related asthma: American College of Chest Physicians consensus statement. Chest. 2008;134(3 Suppl):1S-41S, http://dx.doi. org/10.1378/chest.08-0201.

3. Fishwick D. Work aggravated asthma; A review of the recent evidence. Br Med Bull. 2014;110(1):77-88, http://dx.doi.org/ 10.1093/bmb/ldu004.
4. Henneberger PK, Liang X, Lillienberg L, Dahlman-Hoglund A, Toren K, Andersson E. Occupational exposures associated with severe exacerbation of asthma. Int J Tuberc Lung Dis. 2015;19(2):244-50, http://dx.doi.org/10.5588/ ijtld.14.0132.

5. Mazurek JM, White GE; Centers for Disease Control and Prevention. Work-related asthma - 22 states, 2012. MMWR Morb Mortal Wkly Rep. 2015;64(13):343-6.

6. White GE, Mazurek JM, Storey E. Employed adults with asthma who have frequent workplace exposures. J Asthma. 2015;52(1):46-51, http://dx.doi.org/10.3109/02770903. 2014.944984.

7. Henneberger P, Liang X, Lemiere C. A comparison of work-exacerbated asthma cases from clinical and epidemiological settings. Can Respir J. 2013;20(3):159-64.

8. Lemiere C, Forget A, Dufour MH, Boulet LP, Blais L. Characteristics and medical resource use of asthmatic subjects with and without work-related asthma. J Allergy Clin Immunol. 2007;120(6):1354-9, http://dx.doi.org/10.1016/ j.jaci.2007.07.043.

9. Chiry S, Cartier A, Malo JL, Tarlo SM, Lemiere C. Comparison of peak expiratory flow variability between workers with work-exacerbated asthma and occupational asthma. Chest. 2007;132(2):483-8, http://dx.doi.org/10.1378/ chest.07-0460.

10. Lemiere C, Begin D, Camus M, Forget A, Boulet LP, Gerin M. Occupational risk factors associated with work-exacerbated asthma in Quebec. Occup Environ Med. 2012;69(12): 901-7, http://dx.doi.org/10.1136/oemed-2012-100663.

11. Lemiere C, Boulet LP, Chaboillez S, Forget A, Chiry S, Villeneuve $\mathrm{H}$, et al. Work-exacerbated asthma and occupational asthma: Do they really differ? J Allergy Clin Immunol. 2013;131(3):704-10, http://dx.doi.org/10.1016/j.jaci. 2012.08.024.

12. Lemiere C, To T, de Olim C, Ribeiro M, Liss G, Lougheed MD, et al. Outcome of work-related asthma exacerbations in Quebec and Ontario. Eur Respir J. 2015;45(1): 266-8, http://dx.doi.org/10.1183/09031936.00096114. 
13. Santos MS, Jung H, Peyrovi J, Lou W, Liss GM, Tarlo SM. Occupational asthma and work-exacerbated asthma: Factors associated with time to diagnostic steps. Chest. 2007;131(6):1768-75, http://dx.doi.org/10.1378/chest. 06-2487.

14. Vandenplas O, Henneberger PK. Socioeconomic outcomes in work-exacerbated asthma. Curr Opin Allergy Clin Immunol. 2007;7(3):236-41, http://dx.doi.org/10.1097/ ACI.0b013e3280b10d68.

15. Liss GM, Buyantseva L, Luce CE, Ribeiro M, Manno M, Tarlo SM. Work-related asthma in health care in Ontario. Am J Ind Med. 2011;54(4):278-84, http://dx.doi.org/10.1002/ ajim.20935.

16. Lim T, Liss GM, Vernich L, Buyantseva L, Tarlo SM. Workexacerbated asthma in a workers' compensation population. Occup Med (Lond). 2014;64(3):206-10, http://dx.doi. org/10.1093/occmed/kqu001.

17. Ribeiro M, Buyantseva LV, Liss GM, Luce CE, Tarlo SM. Impact of a cleaners' strike on compensation claims for asthma among teachers in Ontario. Can Respir J. 2013;20(3):171-4.

18. Nicholson PJ, Cullinan P, Newman Taylor AJ, Burge PS, Boyle C. Evidence based guidelines for the prevention, identification, and management of occupational asthma. Occup Environ Med. 2005;62(5):290-9, http://dx.doi.org/10.1136/ oem.2004.016287.

19. Newman Taylor AJ, Cullinan P, Burge PS, Nicholson P, Boyle C. BOHRF guidelines for occupational asthma.
Thorax. 2005;60(5):364-6, http://dx.doi.org/10.1136/thx. 2004.032367.

20. Wiszniewska M, Walusiak-Skorupa J. Diagnosis and frequency of work-exacerbated asthma among bakers. Ann Allergy Asthma Immunol. 2013;111(5):370-5, http://dx.doi. org/10.1016/j.anai.2013.08.004.

21. Tarlo SM. Laboratory challenge testing for occupational asthma. J Allergy Clin Immunol. 2003;111(4):692-4, http:// dx.doi.org/10.1067/mai.2003.1374.

22. Vandenplas O, Wiszniewska M, Raulf M, de Blay F, Gerth van Wijk R, Moscato G, et al. EAACI position paper: Irritant-induced asthma. Allergy. 2014;69(9):1141-53, http:// dx.doi.org/10.1111/all.12448.

23. Ghajar-Khosravi S, Tarlo SM, Liss GM, Chignell M, Ribeiro M, Levinson AJ, et al. Development of a web-based, work-related asthma educational tool for patients with asthma. Can Respir J. 2013;20(6):417-23.

24. Killorn KR, Dostaler SM, Olajos-Clow J, Turcotte SE, Minard JP, Holness DL, et al. The development and test re-test reliability of a work-related asthma screening questionnaire. J Asthma. 2015 Apr;52(3):279-88, http://dx.doi.org/10.3109/ 02770903.2014.956892.

25. Killorn KR, Dostaler SM, Groome PA, Lougheed MD. The use of a work-related asthma screening questionnaire in a primary care asthma program: An intervention trial. J Asthma. 2015 May;52(4):398-406, http://dx.doi.org/10.310 9/02770903.2014.971966.

This work is available in Open Access model and licensed under a Creative Commons Attribution-NonCommercial 3.0 Poland License - http://creativecommons.org/ licenses/by-nc/3.0/pl/deed.en. 